Int. J. Electrochem. Sci., 11 (2016) $7343-7358$

International Journal of

ELECTROCHEMICAL

SCIENCE

www.electrochemsci.org

\title{
Electrochemical Impedance Spectroscopy Investigations of Steel Corrosion in Acid media in the presence of Thiophene Derivatives
}

\author{
S. Ben Aoun ${ }^{1, *}$, M. Bouklah ${ }^{2, * *}$, K.F. Khaled ${ }^{3}$, B. Hammouti $^{2, * * *}$ \\ ${ }^{1}$ Department of Chemistry, Faculty of Science, Taibah University, PO Box 30002 Al-Madinah \\ Al-Munawarah, KSA. \\ ${ }^{2}$ Laboratory of Applied Chemistry and Environment (LCAE), Faculty of Science, Mohammed Premier \\ University, B.P. 717, M-6000 Oujda, Morocco \\ ${ }^{3}$ Materials and corrosion laboratory (MCL), Chemistry Department, Taif University, P.O. 888, Taif, \\ KSA. \\ *E-mail: sbenaoun@taibahu.edu.sa \\ **E-mail: boukmmm@yahoo.fr \\ ***E-mail:hammoutib@gmail.com
}

doi: $10.20964 / 2016.09 .07$

Received: 6 April 2016 / Accepted: 19 June 2016 / Published: 7 August 2016

Reinforcing steel corrosion behavior in the presence of 2-(thiophen-3-yl)ethanamine (3ET) and 2-(thiophen-2-yl)ethanamine (2ET) was studied using Electrochemical impedance spectroscopy. Both pit growth and corrosion of steel were inhibited with either compound present in the corroding medium. (EIS) measurements permitted the investigation of concentration, immersion time and the applied potential effects. Inhibition efficiencies up to ca. $86.22 \%$ and ca. $86.51 \%$ were achieved in the presence of $5 \times 10^{-3} \mathrm{M}(2 \mathrm{ET})$ and (3ET), respectively.

Keywords: EIS, thiophene, inhibition, steel, potential of zero charge (PZC), Equivalent circuit

\section{FULL TEXT}

(C) 2016 The Authors. Published by ESG (www.electrochemsci.org). This article is an open access article distributed under the terms and conditions of the Creative Commons Attribution license (http://creativecommons.org/licenses/by/4.0/). 